\title{
JETDE Preface
}

\author{
Timothy Newby
}

One of the real pleasures of working and studying in the field of Educational Technology and Instructional Design is being able to see the wide variety of content that is covered but yet the consistent, common underlying focus that always leads one back to the topic of learning. This set of articles in JETDE, volume 5 number 2 will not disappoint in that regard. While the participants, methodologies, and the content of the interventions may differ, each of the authors looks to find ways to impact the learning of their audiences.

The study by Shaoqing Guo and Yanjun Yang brings to light the need to find authentic methods to evaluate the impact of teacher development training on overall student learning. In this large pilot study involving teachers from 80 different schools, teachers were trained on how to facilitate project based learning activities with their students as well as how to collaborate with similarly trained teachers at schools in other locations. Following the professional development training, teachers from high and low resource divergent level schools were paired and collaborated on independent PBL projects in their individual classes. This designallowed teachers to practice their PBL facilitation in an environment that facilitated peer-to-peer collaboration and feedback, as their students experienced multiple PBL activities. Using both qualitative and quantitative methods of data collection, teacher beliefs, level of knowledge and comprehension, and teaching behaviors were shown to improve. Likewise, a positive impact on student overall attitudes about school, as well as a positive impact on their subject matter knowledge and comprehension were reported. High value is found in this study's intervention of not only the initial professional development training, but also in how the training is then utilized repeatedly within the classroom setting. Moreover, connecting teachers together to collaboratively work on the PBL projects allowed for additional peer to peer insights to be garnered on how to effectively implement the training.

Jui-Long Hung, Kerry Rice, and Anthony Saba in their article, discuss various forms of data that can and are being collected in typical online courses through the use of learning or course management systems. Moreover, these data provide unique research opportunities to ascertain and analyze specific predictors of students' academic performance based upon their course work and responses. Data analytics could then identify interventions for performance improvement. The authors review what literature exists on educational data mining (EDM) and then propose a straightforward model to provide research guidance on the analytic processes of EDM. This is an important, yet still relatively new field within educational research. With the use of a case study of 4 sections of two different online courses, these authors were able to utilize and demonstrate their model to highlight how well it can be used to obtain the needed information and what can be gained from that data.

In her paper, Yan Sun reviews the extensive efforts that have gone into preparing teachers for the integration of technology, as well as the increased classroom access to computers and the Internet; then she asks the important question of why haven't these efforts been accompanied 
by an equal growth of consistent quality technology integration? After an in-depth discussion of the barriers to integration and the challenges they impose, Sun proposes the EMPIRe Model for technology integration. Each section of the model (Evaluating, Matching, Planning, Implementing, and Reflection) is described with a focus on how they combine to promote learning by thinking through the integration of the technology. A truly significant contribution of this article is Sun's straight forward explanation of how the model is used to guide and inform the process of technology integration as one designs and implements instructional materials; moreover, how it can also be used as an evaluation tool as one observes technology integration being modeled by others.

In the paper, "Development and evaluation of an educational computer game for a certification examination" researchers Gwo-Haur Hwang, Chen-Yu Lee, and Wei-Fang Tseng compared the learning and performance of groups of students taught in a traditional e-learning version with a more game based version of the certification training. Although their numbers of participants were limited and their overall findings showed non-significant differences between the two versions of the training, this study serves as a solid demonstration of how to examine the literature, identify key research questions, andconstruct and analyze a research study to compare different levels of an independent variable across different levels of participant knowledge and experience. These authors help us to see the possibilities of this type of research and where future research would prove most beneficial.

Chientzu Candace Chou, Lanise Block, and Renee Jesness present an interesting case study focused on a pilot project using iPads within full geography classrooms of K-12 students. After discussing the benefits and challenges reported in previous research of using mobile technologies within the classroom setting, these authors investigate the factors that contribute, as well as those that inhibit, student learning and teachers' facilitation of learning with mobile devices (i.e., iPads). Using qualitative measures involving student focus groups and classroom observations, results focused on the level of student engagement, time on projects, information literacy, digital citizenship, as well as distractions are discussed. From data gathered through teacher focus groups and classroom observations, teacher benefits of increased student-centered activities and enhanced teaching with updated information were noted. While additional challenges to the teachers included the lack of teacher selected apps and the need for additional training. An important contribution is made within this study as the authors explore these mobile technologies from the perspective of the students as well as the teachers that were involved.

The case study presented by S. J. Fu, J. S. Huang, J. H. Yang, and Y. Q. Huang is an interesting look at the potential use of e-portfolios with undergraduate participants studying within a science discipline. In particular, this study examined how students used the provided e-portfolio platform to demonstrate their achieved learning stages, as well as to what degree they reflected upon the learning process. While results were limited by the low student voluntary selection and use of the platform, the authors make an important contribution with their coding scheme that helps identify higher versus lower levels of learning stages based upon participant written statements and reflections within the e-portfolio.

Following a TPACK training model, Hsiu-Jen Cheng and Hong Zhan first trained and then measured the development of instructional strategies in pre-service teachers of foreign languages. 
In a unique case study, these authors used action research methodology to examine how the training given to the pre-service teachers was implemented within actual live teaching situations. Using synchronous video conferencing software, the pre-service teachers taught students in a different country specific foreign language lessons. The results of their work highlight specific instructional strategies that were selected and used by the teachers and which of those were found to be appropriate for learning (e.g., the use of graphics, body language, review strategies) and which strategies that were less appropriate (e.g., use of misleading or meaningless pictures, overuse of animations). The authors conclude with an interesting discussion of the training of pre-service teachers in the use of technology, content, and pedagogy.

The study presented by Yu Yan, Xibin Han, Juan Yang and Qian Zhou aims at designing a web-based system to support the Master's degree thesis research process and the knowledge sharing that is required in that setting. These authors begin by identifying the main steps of the thesis research process, and then they propose an instructional model based on the analysis of the practical thesis research workflow and relevant instructional approaches, such as problembased learning, cognitive apprenticeship learning, and collaborative learning. According to the above instructional model and the software designing principle, six principles for designing a web-based system for supporting master degree thesis research process and knowledge sharing were presented. Furthermore, a software system called THEOL is designed and developed. A preliminary evaluation of the system was conducted and the results showed that the system was effective to support the thesis research by providing multi-supervision in the research process and knowledge sharing.

I was excited to read, examine, and reflect on each of these articles. I found myself pondering about their implications for the field and my own work in particular. I hope that you will take the time to consider these contributions as well. 